\title{
Prevention of aflatoxin contamination of maize by Aspergillus flavus through aqueous plant extracts in Saudi Arabia
}

\author{
Abeer R. M. Abd El-Aziz ${ }^{1 *}$, Monira R. Al-Othman ${ }^{1}$, Saleh A. Al-Sohaibani ${ }^{1}$, Mohamed A. \\ Mahmoud $^{1,2}$ and Kasi Murugan ${ }^{1}$ \\ ${ }^{1}$ Botany and Microbiology Department, College of Science, King Saud University, Riyadh 1145, Kingdom of Saudi \\ Arabia. \\ ${ }^{2}$ Plant Pathology Research Institute, ARC, Giza, Egypt.
}

Accepted 10 September, 2012

\begin{abstract}
The efficacy of four concentrations of aqueous extracts of 11 local plants in the management of Aspergillus flavus and aflatoxin contamination was investigated by measuring the dry weight of $A$. flavus. The extracts of Allium sativum gave the best results, decreasing the dry weight of the fungus, followed by Aloe vera, whereas $20 \%$ Coriandrum sativum extract had no significant effect on the fungal dry weight. Aqueous $20 \%$ extracts of the herb Thymus vulgaris and the rhizome of Zingiber officinalis most strongly inhibited aflatoxin production for B1 (79.1\%), followed by the leaf extracts of Olea europaea and Eucalyptus globulus (75.0\%), although the effect on $A$. flavus growth was moderate. The herb T. vulgaris and extract of Ocimum basilicum leaf showed the strongest inhibition of B2 (76.2\%). Conversely, the leaf extracts of Zizyphus spina and Cassia italica produced only marginal effects on the percentage of inhibition of aflatoxins B1 and B2. No positive correlation was observed between mycelial growth and aflatoxin production in $A$. flavus.
\end{abstract}

Key words: Maize, Aspergillus flavus, aflatoxin, aqueous plant extracts.

\section{INTRODUCTION}

Aflatoxins are secondary metabolites of Aspergillus spp. molds, which can grow on a wide variety of agricultural commodities. Aflatoxins are toxic and carcinogenic, cause crop losses and represent a significant hazard to the food chain (Magan and Aldred, 2007). The use of plant extracts with anti-microbial and antifungal properties has been of wide interest in efforts to remove these aflatoxins from food and feed. Aspergillus flavus can produce the aflatoxins B1, B2, G1 and G2 in sorghum (Yassin et al., 2010). Aspergillus spp produce aflatoxins in starchy cereal grains, such as maize, wheat, sorghum, barley, millet and rice, and contamination can occur in the field, at harvest, during post-harvest operations and during storage. Additionally, the rate and degree of aflatoxin contamination are dependent on the temperature,

\footnotetext{
${ }^{\star}$ Corresponding author. E-mail: aabdelaziz@ksu.edu.sa.
}

humidity, soil and storage conditions (Mojatahedi et al 1974).

Maize is one of the most important cereal crops in the world, with a global harvested area of 159.53 million ha, of which 20.907 million ha are harvested in Saudi Arabia, and a total worldwide yield of 817.1 million tons (FAO, 2009). Aflatoxin contamination of maize is an important problem in warm, humid regions in which Aspergillus may infect the crop prior to harvest and remain viable during storage. Indeed, thousands of camels in Saudi Arabia may have been killed by the consumption of aflatoxincontaminated fodder (Bokhari, 2010). Growing concerns about food safety have led to the development of natural antimicrobials for food preservation.

Plant extracts have demonstrated antimicrobial effects mediated by several compounds, such as phenolics, flavonoids, allicin, thiosulfinates, betalain and phytoalexins (Harris et al., 2001; Beevi et al., 2009), and there is an ongoing and urgent need to discover new antimicro- 
Table 1. Plant species, family, common name and plant parts used in the study.

\begin{tabular}{lllc}
\hline Plant specie & Family & Common name & Plant part used \\
\hline Allium cepa & Alliaceae & onion & $\mathrm{B}$ \\
Allium sativum & Alliaceae & Garlic & $\mathrm{B}$ \\
Aloe vera & Xanthorrhoeaceae & Aloe & $\mathrm{L}$ \\
Cassia italica & Fabaceae & Cassia & $\mathrm{L}$ \\
Coriandrum sativum & Apiaceae & Coriander & $\mathrm{L}$ \\
Eucalyptus globolus & Myrtaceae & Eucalyptus & $\mathrm{L}$ \\
Ocimum basilicum & Lamiaceae & Basil & $\mathrm{L}$ \\
Olea europaea & Oleaceae & olive & $\mathrm{L}$ \\
Thymus vulgaris & Lamiaceae & Thyme & $\mathrm{L}$ \\
Zingiber officinalis & Zingiberaceae & Ginger & $\mathrm{R}$ \\
Zizyphus spina & Rhamnaceae & Seder & $\mathrm{L}$ \\
\hline
\end{tabular}

$\mathrm{L}=$ Leaves, $\mathrm{B}=$ Bulbs, $\mathrm{R}=$ Rhizomes.

bial compounds with diverse chemical structures and novel mechanisms of action (Parekh and Chanda, 2010). Therefore, the goal of the present study was to investigate the antiaflatoxigenic activities of the aqueous extracts Aloe vera, Cassia italica, Datura stramonium, Eucalyptus globulus, Lavandula vera, Lawsonia inermis, Olea europaea, Prosopis juliflora, Ricinus communis and Zizyphus spina, as certain medicinal plants and spices have been reported to be useful in inhibiting aflatoxin production (El Shayeb and Mabrouk 1984; Madhyastha and Bhat 1985).

In the present study, the effects of each plant extract on $A$. flavus aflatoxin production were evaluated with the goal of developing a cost-effective method for preventing aflatoxin contamination of maize in Saudi Arabia.

\section{MATERIALS AND METHODS}

\section{Fungal isolation}

Ten samples of maize were collected from different localities of Riyadh, Kingdom of Saudi Arabia. The maize seeds were disinfected using $2 \%$ sodium hypochlorite for two minutes, rinsed three times in sterile distilled water and dried between layers of sterile filter paper (Whatman No. 1). Then, five grains were placed randomly onto potato dextrose agar (PDA) and incubated at $25 \pm 2{ }^{\circ} \mathrm{C}$ for 7 days. The isolates obtained were purified by the single-spore method and then transferred to PDA slants. The fungal isolates were identified based on their morphological and microscopic characteristics according to the method proposed by Dugan (2006).

\section{Preparation of the plant extracts}

Materials from eleven plant species are shown in Table 1 (A. vera, C. italica, D. stramonium, E. globulus, L. vera, L. inermis, O. europaea, $P$. juliflora, Ricinus communis and $Z$. spina) belonging to nine botanical families (Table 1) were washed with tap water, disinfected by immersion in $2 \%$ sodium hypochlorite solution for $30 \mathrm{~min}$, rinsed with sterile distilled water to eliminate residual hypochlorite and dried in the shade.

The shade-dried materials of each plant species were then ground into a powder using a blender in distilled water at rate of $100 \mathrm{gm} / 100 \mathrm{ml}$ water (For preparation concentration 100\%). The macerated materials were squeezed through double cheese cloth sheets then filtered through filter paper whattman No.(1). The filtrates were centrifuged at $5000 \mathrm{rpm}$ for $30 \mathrm{~min}$ and sterilized by Seitz's filter according to the method proposed by Ismail et al. (1989). Different concentrations were added to media before inoculation with the fungus.

\section{Antifungal activity of the plant extracts}

The antifungal activity was evaluated using the toxigenic $A$. flavus strain with Czapek Dox broth medium (sucrose, $30 \mathrm{~g}$; sodium nitrate, $3 \mathrm{~g}$; dipotassium phosphate, $0.5 \mathrm{~g}$; magnesium sulfate, 0.5 $\mathrm{g}$; potassium chloride, $0.5 \mathrm{~g}$; ferrous sulfate, $0.01 \mathrm{~g}$ and distilled water, $1000 \mathrm{ml}, \mathrm{pH}, 6.5)$. The plant extracts were added to the medium at four concentrations $(5.0,10.0,15.0$ and $20.0 \%)$ before inoculation with the fungus. A control without plant extracts was included. Flasks were inoculated with $5 \mathrm{~mm}$ diameter discs of the toxigenic $A$. flavus isolate and incubated at $25 \pm 2^{\circ} \mathrm{C}$ for 7 days. After incubation, the contents of each flask were filtered (Whatman No. 1), and the biomass of the filtered mycelia was determined after being dried at $70^{\circ} \mathrm{C}$ for 4 days until the weights stabilized. The percent mycelial inhibition was calculated using the following formula according to Mostafa et al. (2011).

Percent mycelial inhibition $=[\mathrm{C}-\mathrm{T} / \mathrm{C}] \times 100$

Where, $C$ is the dry weight of the control $(g)$, and $(T)$ is the dry weight of the treatment with the tested extract.

\section{Aflatoxin inhibition}

The minimal inhibitory concentration (MIC) and antiaflatoxigenic efficacy values of each plant extract were determined using SMKY liquid medium (sucrose, $20 \mathrm{~g}$; magnesium sulfate, $0.5 \mathrm{~g}$; potassium nitrate, $3 \mathrm{~g}$; yeast extract, $7 \mathrm{~g}$ and distilled water, $1000 \mathrm{ml}$ ) (ElSamawaty, et al., 2011). Different concentrations of each plant extract $(5,10,15$ and $20 \%)$ were prepared separately and added to $100 \mathrm{ml}$ flasks, which were incubated at $25 \pm 2^{\circ} \mathrm{C}$ for 7 days. After incubation, the cultures were blended using a high-speed homogenizer and filtered through Whatman No. 1 filter paper. The aflatoxins were extracted from the filtrates using a mixture of chloroformacetone $(9 / 1 \mathrm{v} / \mathrm{v})$. The dried residues were dissolved in 
Table 2. Antifungal screening of eleven aqueous plant extracts at five concentrations against the mycelial dry weight ( $g$ ) of Aspergillus flavus isolated from maize.

\begin{tabular}{|c|c|c|c|c|c|c|}
\hline Plant species & $0 \%$ & $5 \%$ & $10 \%$ & $15 \%$ & $20 \%$ & LSD \\
\hline Allium cepa & ${ }^{\mathrm{A}} 3.83^{\mathrm{a}} \pm 0.19$ & ${ }^{B} 3.20^{C *} \pm 0.18$ & ${ }^{B} 3.15^{C_{*}} \pm 0.04$ & ${ }^{\mathrm{C}} 2.55^{\mathrm{b} *} \pm 0.13$ & $\mathrm{c}^{\mathrm{c}} 2.72^{\mathrm{b} *} \pm 0.03$ & 0.417 \\
\hline Allium sativum & ${ }^{\mathrm{A}} 3.83^{\mathrm{a}_{*}} \pm 0.19$ & ${ }^{C_{2}} 2.17^{\mathrm{e}_{*}} \pm 0.08$ & ${ }^{B} 2.80^{d_{*}} \pm 0.07$ & $\mathrm{D}_{1.20^{\mathrm{d}_{*}} \pm 0.15}$ & ${ }^{E} 0.60^{h_{*}} \pm 0.03$ & 0.374 \\
\hline Aloe vera & ${ }^{\mathrm{A}} 3.83^{\mathrm{a}_{*}} \pm 0.19$ & ${ }^{\mathrm{B}} 2.17^{\mathrm{e} *} \pm 0.04$ & $\mathrm{C}_{1.54^{\mathrm{g}_{*}} \pm 0.06}$ & $\mathrm{D}_{1.04^{\mathrm{d} *} \pm 0.10}$ & $\mathrm{D}_{1.00^{g *} \pm 0.00}$ & .314 \\
\hline Cassia italica & ${ }^{A} 3.83^{\mathrm{a}_{*}} \pm 0.19$ & $\mathrm{~A}_{3.61^{\mathrm{ab}_{*}} \pm 0.08}$ & ${ }^{\mathrm{A}} 3.43^{\mathrm{b} *} \pm 0.06$ & $\mathrm{~B}_{1.80^{\mathrm{C} *} \pm 0.16}$ & $c_{1.32^{f_{*}} \pm 0.06}$ & 379 \\
\hline Coriandrum sativum & ${ }^{\mathrm{A}} 3.83^{\mathrm{a} *} \pm 0.19$ & ${ }^{A} 3.79^{a *} \pm 0.05$ & ${ }^{\mathrm{A}} 3.84^{\mathrm{a} *} \pm 0.05$ & $\mathrm{AB}_{3 .} 34^{\mathrm{a*}} \pm 0.19$ & ${ }^{\mathrm{B}} 3.11^{\mathrm{a} *} \pm 0.20$ & 0.473 \\
\hline Eucalyptusgobuglobolus & ${ }^{\mathrm{A}} 3.83^{\mathrm{a} *} \pm 0.19$ & ${ }^{B} 3.29^{C *} \pm 0.07$ & ${ }^{\mathrm{B}} 3.25^{\mathrm{bc} *} \pm 0.10$ & ${ }^{c} 2.63^{b *} \pm 0.10$ & $\mathrm{C}_{2.27^{\mathrm{C} *} \pm 0.16}$ & 0.406 \\
\hline Ocimum basilicum & ${ }^{\mathrm{A}} 3.83^{\mathrm{a} *} \pm 0.19$ & ${ }^{\mathrm{B}} 2.64^{\mathrm{d} *} \pm 0.04$ & $\mathrm{C}_{2.14^{f_{\star}} \pm 0.06}$ & $\mathrm{D}_{1.78^{\mathrm{C} *} \pm 0.07}$ & $\mathrm{D}_{1.77^{\mathrm{de} *} \pm 0.06}$ & 0.309 \\
\hline Olea europaea & ${ }^{\mathrm{A}} 3.83^{\mathrm{a} *} \pm 0.19$ & ${ }^{\mathrm{B}} 2.77^{\mathrm{d} *} \pm 0.05$ & ${ }^{\mathrm{B}} 2.78^{\mathrm{d}} \pm 0.06$ & $\mathrm{c}_{2.15^{\mathrm{c} *} \pm 0.09}$ & $\mathrm{D}_{1.60^{\mathrm{ef}_{*}} \pm 0.05}$ & 0.318 \\
\hline Thymus vulgaris & ${ }^{\mathrm{A}} 3.83^{\mathrm{a}{ }_{*}} \pm 0.19$ & ${ }^{\mathrm{B}} 3.19^{\mathrm{C} *} \pm 0.07$ & $\mathrm{C}_{2.83^{\mathrm{d}} \pm 0.06}$ & $\mathrm{D}_{1.88^{\mathrm{C}_{*}} \pm 0.06}$ & $\mathrm{D}_{1.91^{\mathrm{d}} \pm} \pm 0.10$ & 0.336 \\
\hline Zingiber officinalis & ${ }^{A} 3.83^{\mathrm{a}_{*}} \pm 0.19$ & ${ }^{B} 2.83^{d_{*}} \pm 0.04$ & ${ }^{\mathrm{B}} 2.42^{\mathrm{e}} \pm 0.16$ & $\mathrm{c}_{1.90^{\mathrm{c} *} \pm 0.17}$ & 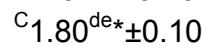 & 0.443 \\
\hline Zizyphus spina & ${ }^{A} 3.83^{a_{*}} \pm 0.19$ & ${ }^{A} 3.54^{b *} \pm 0.03$ & ${ }^{\mathrm{B}} 2.47^{\mathrm{e} *} \pm 0.14$ & $\mathrm{c}_{1.96^{\mathrm{C}_{*}} \pm 0.09}$ & $\mathrm{c}_{1.93^{\mathrm{d}_{*}} \pm 0.08}$ & 0.374 \\
\hline$\angle S D$ & 0.543 & 0.228 & 0.254 & 0.369 & 0.281 & \\
\hline
\end{tabular}

Values in the same column followed by an asterisk $\left({ }^{*}\right)$ are significantly different $(P=0.05)$. The data shown are the means $(n=3)$ \pm standard error of three replicates, data followed by the same letter are not significant at $P \leq 0.05$, but followed by different letters are significant at $\mathrm{P} \leq 0.05$ ).

a mixture of methanol: acetic acid: water $(20: 20: 60 \mathrm{v} / \mathrm{v} / \mathrm{v})$, and the toxins were measured using high-performance liquid chromatography (HPLC) (model PerkinElmer series 200 UV/VIS) with a C18 column with an internal diameter of $100 \times 4.6 \mathrm{~mm}$. The total run time for the separation was approximately $25 \mathrm{~min}$ at a flow rate of 1 $\mathrm{ml} / \mathrm{min}$.

The aflatoxin inhibition was calculated according to Mostafa et al. (2011) as follows:

Percentage of inhibition toxin $=[A-a / A] \times 100$,

where " $A$ " is the concentration of aflatoxin in the treated sample and "a" is the concentration of aflatoxin in the control.

\section{Statistical analysis}

All measurements were replicated three times for each treatment, and the data were reported as the mean \pm SE (standard error). The data were also analyzed statically using a one-way analysis of variance (ANOVA), and the differences among the means were evaluated for significance at $P \leq 0.05$ using Duncan's multiple range test in SPSS, 16.1 (SPSS, Chicago, USA).

\section{RESULTS}

The efficacy of selected local plants in the management of $A$. flavus and aflatoxin contamination was investigated. The botanical and common names of the eleven plants belonging to nine families and the different parts are used in this study. The aqueous extracts of the plants were screened for their ability to reduce the dry weight and aflatoxin production of $A$. flavus. The effects of the 11 aqueous plant extracts on dry weight of $A$. flavus at four concentrations are shown in Table 2. The plant extracts show varying abilities to suppress $A$. flavus grown in a broth medium, and the inhibitory effect of the extracts increased in proportion to their concentrations, reaching a maximum at the highest concentration. The analysis of variance of the dry weight of $A$. flavus revealed interac- tions between the plant extract and extract concentration, and the interactions were highly significant $(P \leq 0.05)$ (Table 1). All the tested aqueous plant extracts caused a significant decrease in the dry weight at a high concentration. The aqueous extract of $A$. sativum was the most effective in inhibiting the fungal dry weight $(0.60 \mathrm{gm})$, followed by $20 \%$ A. vera $(1.0 \mathrm{gm})$ and $20 \%$ C. italica (1.32 gm), whereas $20 \%$ C. sativum $(3.11 \mathrm{gm})$ was only marginally effective in reducing the fungal dry weight.

Table 3 reveals that all 11 aqueous plant extracts were effective inhibitors of $A$. flavus aflatoxin production at the four concentrations tested. The aqueous extracts of the herb Thymus vulgaris and the rhizome of Zingiber officinalis at $20 \%$ concentrations strongly inhibited B1 aflatoxin production inhibition $(79.1 \%)$, followed by the aqueous leaf extracts of $O$. europaea and E. globulus (75.0\%), although the $A$. flavus growth inhibition was moderate.

In contrast, the extracts of the herb $T$. vulgaris and the leaf of Ocimum basilicum were the most effective in inhibiting B2 (76.2\%). Conversely, the leaf extracts of $Z$. spina and $C$. italica had only marginal effects on aflatoxin B1 and B2 production (16.6 and 9.5, and 25.0 and $23.8 \%$, respectively).

The results of the present investigation suggest that plant extracts can be exploited for the management of mold infestation and the mycotoxin contamination of food. However, no correlation between the growth of the fungus and aflatoxin synthesis was found.

\section{DISCUSSION}

As alternative control measures to replace conventional synthetic pesticides, we screened eleven plant species (Allium cepa, A. sativum, A. vera, C. italica, C. sativum, E. globulus, O. basilicum, O. europaea, T. vulgaris, Z. officinalis and $Z$. spina) for their inhibitory effects on the toxin 
Table 3. The efficacy of selected plant extracts as antiaflatoxins at $20 \%$.

\begin{tabular}{lcccc}
\hline Plant specie & B1 $(\mathbf{p p b})$ & Inhibition of aflatoxin B1 (\%) & B2 (ppb) & Inhibition of aflatoxin B2 (\%) \\
\hline Allium cepa & 7 & 70.8 & 8 & 61.9 \\
Allium sativum & 11 & 54.2 & 13 & 38.1 \\
Aloe vera & 10 & 58.3 & 12 & 42.8 \\
Cassia italica & 18 & 25.0 & 16 & 23.8 \\
Coriandrum sativum & 12 & 50.0 & 9 & 57.1 \\
Eucalyptus globulus & 6 & 75.0 & 7 & 66.7 \\
Ocimum basilicum & 7 & 70.8 & 5 & 76.2 \\
Olea europaea & 6 & 75.0 & 8 & 61.9 \\
Thymus vulgaris & 5 & 79.1 & 5 & 76.2 \\
Zingiber officinalis & 5 & 79.1 & 7 & 66.7 \\
Zizyphus spina & 20 & 16.6 & 19 & 9.5 \\
Control & 24 & 0.0 & 21 & 0.0 \\
\hline
\end{tabular}

production by $A$. flavus. Aflatoxin contamination has been reported in many foods. In addition, plants such as $E$. globulus, O. europaea, Salvadora persica, T. vulgaris and $Z$. spina-christi have been studied for antifungal activities against $A$. flavus (Al-Rahmah et al., 2011). A. sativum, Aframomum melegueta and $Z$. officinale have been reported to inhibit aflatoxin production by $A$. flavus (Ayodele et al., 2009). Salim (2011) found that aqueous extracts of beet root, garlic, leek, radish and turnip could be applied as natural food preservatives against fungal mycotoxin production and that plant extracts can suppress aflatoxin biosynthesis.

The variation in the efficacies of the tested plant extracts against the toxigenic $A$. flavus may be due to the considerable variation in their constituents (Cavaleiro et al., 2006; Rosca- Casian et al., 2007). The anti-fungal properties of these extracts may also be attributed to their distinct phytochemical contents; these molecules, including alkaloids, phenols, glycosides, steroids, essential oils and tannins, may each cause different inhibitory effects (Mostei et al., 2003; Rasoolil et al., 2009).

Other researchers have suggested that the antimicrobial components of the plant extracts cross the cell membrane and interact with the resident membrane proteins, producing a flux of protons toward the cell exterior that induces changes in the cell and, ultimately, cell death (Omidbeygi et al., 2007). However, the inhibitory potential may depend on the mode of extraction and the concentration of the extracts. Plant extract production can be standardized for the effective use as alternatives to chemicals in the preservation of agricultural products against fungal rot during storage (Ayodele et al., 2009). However, according to Masood and Ranjan (1991) no correlation between fungal growth and aflatoxin synthesis was observed.

\section{ACKNOWLEDGEMENT}

The project was supported by the Research Center, College of Science, King Saud University.

\section{REFERENCES}

Al-Rahmah N, Mostafa A, Abdel-Megeed A (2011). Antifungal and antiaflatoxigenic activities of some plant extracts. Afri. J. Microbiol. Res. 5(11):1342-1348.

Ayodele S, londu MIE, Onwubolu NC (2009). Antifungal properties of some locally used spices In Nigeria against some rot fungi. Afri. J. Plant Sci. 3(6):139-141.

Beevi SS, Mangamoori IN, Vivek D, Ramakrishna VDS (2009). Isothiocyanate profile and selective antibacterial activity of root steem and leaf extracts derived from Raphanus satives L. Food Borne Patho. Dis. 6:129-136.

Bokhari FM (2010). Implications of fungal infections and mycotoxins in camel diseases in Saudi Arabia. Saudi J. Biol. Sci. 17:73-81.

Cavaleiro C, Pinto E, Goncalves MJ, Salguerio L (2006). Antifungal activity of Junipers essential oils against dermatophytes, Aspergillus and Candida strains. J. Appl. Microbiol. 100:1333-1338.

Dugan FM (2006). The identification of fungi:an illustrated introduction with keys, glossary and guide to literature. Am. Phytopathol. Soc. p. 179.

El Samawaty MA, Yassin MA, Bahkali A, Moslem M, Abd-Elsalam KA (2011). Bio fungicidal activity of aloe vera sap against mycotoxinogenic seed borne fungi. Frenesenius Environ. Bull. 20(7):1352-1359.

El Shayeb NMA, Mabrouk SS (1984). Utilization of some edible and medicinal plants to inhibit aflatoxin formation. Nutr Rep Int. 29:273 282

FAO (2009). FAOSTAT Database, http://faostat.fao.org/

Harris JC, Cottrell SL, Plummer S, Lloyd D (2001). Antimicrobial properties of Allium sativum (garlic). Appl. Microbiol. Biotechnol. 57:282-286.

Ismail IMK, Salama AAM, Ali MIA Ouf SAE (1989). Bioassay of

Eucalyptus rostorata leaf extractives on Sclerotium cepivorum Berk. Egypt J. Bot. 32(1-2):109-126.

Madhyastha MS, Bhat RV (1985). Evaluation of substrate potentiality and inhibitory effects to identify high risk spices for aflatoxin contamination. J. Food Sci. 58:376-378.

Magan N, Aldred D (2007). Post-harvest control strategies: Minimizing mycotoxins in the food chain. Int. J. Food Microbiol. 119:131-139.

Masood A, Ranjan KS (1991). The effect of aqueous plant extracts on growth and aflatoxin production by Aspergillus flavus. Lett. Appl. Microbiol. 13(1):32-34.

Mojatahedi H, Danesh D, Haghighi B, Barnett R (1974). Post-harvest pathology and mycotoxin contamination of Iranian pistachio nuts. Phytopathol. 68(12):1800-1804.

Mostafa AA, Al-Rahmah AN, Abdel-Megeed A (2011). Evaluation of some plant extracts for their antifungal and antiaflatoxigenic activities. J. Med. Plants Res. 5(17):4231-4238.

Mostei ML, Lindsey KL, Van Staden J, Jager AK (2003). Screening of traditionally used south African plants for antifungal activity against 
Candida albicans. J. Ethnopharmacol. 86:235-241.

Omidbeygi M, Barzegar M, Hamidi Z, Naghdibadi H (2007). Antifungal activity of thyme, summer savory and clove essential oils against Aspergillus flavus in liquid medium and tomato paste. Food Control 18:1518-1523.

Parekh J, Chanda S (2007). In vitro screening of anti Bacterial activity of aqueous and alcoholic extracts of various Indian plant species against selected pathogens from enterobacteriaceae. Aferican G. Microbiol. Res. 6:92-99.

Rasooli I , Fakoor MK, Allameh AA, Rezaee MB, Owlia P (2009).Phytoprevention of aflatoxin production. J. Med. Plants 8(5):97-104.
Rosca-Casian O, Parvu M, Vlase L, Tamas M (2007). Antifungal activity of Aloe vera leaves. Fitoterapia 78:219-222.

Yassin MA, El-Samawaty A, Bahkali A, Moslem M, Abd-Elsalam K, Hyde KD (2010). Mycotoxin-producing fungi occurring in sorghum grains from Saudi Arabia. Fungal Divers. 44:45-52. 